\title{
Implantação de Gerência de Riscos em um Projeto de Software de um Setor Público do MS
}

\author{
Maria Istela Cagnin*, Bruno de Freitas Monteiro, Rebecca França Alves, Thiago \\ Yudi Fukunaga, Vanessa de Moraes Weber, Débora Maria Barroso Paiva
}
Faculdade de Computação - Universidade Federal de Mato Grosso do Sul (UFMS) Caixa Postal 549 - 79.070-900 - Campo Grande - MS - Brasil
\{brunogok, rebeccafalves, thiagoyudifukunaga, vamoraes\}@gmail.com, \{istela, debora\}@facom.ufms.br

Resumo. Muitos projetos de software não obtêm sucesso, pois seus riscos não são gerenciados. Para atender os seus diversos projetos de software uma organização de software deve levar em consideração uma metodologia de Gerência de Riscos que seja dinâmica, efetiva e de rápida aplicação. $O$ objetivo deste artigo é descrever a implantação de uma metodologia de gerência de riscos, chamada RisAgi, em um projeto de software real de um setor público do estado de Mato Grosso do Sul. Após a implantação, foi conduzida uma avaliação e observou-se que a metodologia RisAgi foi fácil de aprender e possibilitou a elaboração de um conjunto mínimo de artefatos suficientes para apoiar a gerência de riscos. Assim, acredita-se que a metodologia RisAgi possa ser implantada de maneira satisfatória em outras organizações de software.

Abstract. Many software projects do not succeed because their risks are not managed. To meet its various software projects, a software company should consider a risk management methodology that is dynamic, effective, and can be implemented rapidly. This paper aims at describing the deployment of a risk management methodology, called RisAgi, in a real software project of a public section of Mato Grosso do Sul state. After the deployment, an evaluation was conducted and the results obtained indicated that the RisAgi methodology was easy to learn and enabled the development of a minimum set of needed artifacts to support risk management. In conclusion, we believed that the RisAgi methodology can be deployed successfully in other software companies.

\section{Introdução}

Uma das maiores causas de fracasso em projetos é a falta de planejamento em relação aos riscos. Sem um bom planejamento, o cronograma pode falhar e os custos podem ser elevados. Essas consequências podem levar a qualidade do projeto a um nível abaixo do esperado ou insatisfatório. Com um bom plano de projeto é possível identificar

\footnotetext{
* Apoio financeiro da Fundect - T.O. n ${ }^{\circ}$ 115/2014 - SIAFEM no 23710.

- Apoio financeiro da Fundect - T.O. n 219/2014 - SIAFEM nº 23963.
} 
possíveis riscos, saber como evitá-los e, caso ocorram, ter um plano de contingência que minimize o impacto dos mesmos (Wazlawick, 2013).

A equipe de Tecnologia de Informação (TI) de uma empresa terceirizada por um setor público do estado de Mato Grosso do Sul (MS) está desenvolvendo um projeto de software, denominado neste artigo por TranWeb ${ }^{\dagger}$. Esse projeto tem como objetivo substituir o sistema atual, que está em uma plataforma tecnológica obsoleta e possui como servidor de dados um mainframe (Laudon e Laudon, 2015), para um novo sistema que será composto por diversos módulos, com seus respectivos submódulos. Para o desenvolvimento do novo sistema estão sendo utilizados tecnologias atuais e processos da engenharia reversa (Pressman, 2016), além de análise de requisitos conforme legislação vigente e necessidades atuais dos clientes.

Como ocorre com outros projetos de aplicações Web, no projeto TranWeb também é importante o gerenciamento de riscos a fim de entregar um produto com qualidade, sem extrapolar prazos e custos inicialmente previstos. Apesar da importância da gerência de riscos, o setor público do MS ainda não possui um processo específico para essa finalidade.

Sob esta perspectiva, este trabalho tem como objetivo geral selecionar na literatura uma metodologia de gerência de riscos para o projeto TranWeb. Com o intuito de avaliar a adequação da metodologia selecionada, a mesma foi utilizada para gerenciar os riscos desse projeto durante o desenvolvimento do módulo $A_{1}$ do subsistema $\mathrm{P}_{1}$. A partir dessa implantação inicial, foram identificados os pontos fortes e fracos da metodologia selecionada para averiguar a viabilidade de sua aplicação durante o desenvolvimento de todo o projeto.

A escrita deste trabalho está organizada em mais cinco seções. Na Seção 2 é apresentada uma visão geral sobre as principais definições e conceitos de gerência de riscos. Na Seção 3 é descrita de forma sucinta uma metodologia para gerência de riscos, denominada RisAgi, encontrada na literatura e descrita de forma detalhada. Na Seção 4 é apresentada a proposta de gerência de riscos para o projeto TranWeb, considerando a implantação da RisAgi no módulo $\mathrm{A}_{1}$ desse projeto. Na Seção 5 são apresentados os resultados e lições apreendidas a partir da avaliação da implantação da RisAgi no setor público do MS, por meio de um questionário respondido por todos os envolvidos. $\mathrm{Na}$ Seção 6 são apresentados trabalhos relacionados e, por fim, na Seção 7 são apresentadas as conclusões do trabalho com a indicação das limitações e sugestões de trabalhos futuros para o enriquecimento do mesmo.

\section{Gerência de Riscos}

Existe um grande desacordo entre os autores da área para definir o termo risco e/ou sua aplicabilidade. Porém, todas as definições relacionam o risco à sua magnitude $\mathrm{e}$ incerteza, o que apresenta uma visão geral do mesmo. A magnitude está relacionada ao impacto causado pelo risco. Diferentemente da incerteza, que está relacionada a uma probabilidade de ocorrência do mesmo (Chamon e Carvalho, 2003).

\footnotetext{
† Por questão de sigilo, os nomes reais do setor público, da empresa terceirizada e do projeto de software não serão revelados.
} 
Entre as diversas definições, neste trabalho é considerada a definição do Project Management Body of Knowledge (PMBOK) (PMI, 2004 apud Wazlawick, 2013), que é referência internacional em gerenciamento de projetos. O PMBOK define que o risco é uma condição incerta que pode ter tanto um efeito positivo quanto um efeito negativo sobre o projeto. Porém, os fatores mais importantes são os riscos que podem prejudicar o projeto (Wazlawick, 2013). O risco pode ser categorizado levando em consideração o conhecimento que se possui sobre ele ou ainda seu impacto no projeto (Wazlawick, 2013).

Em relação ao conhecimento que se tem dos riscos, os mesmos podem ser classificados em (Wazlawick, 2013; Charette, 1989 apud Pressman, 2016): a) riscos conhecidos: são aqueles já identificados e para os quais a equipe possivelmente estará preparada; b) riscos desconhecidos: são aqueles que poderiam ter sido descobertos se as medidas de identificação adequadas tivessem sido tomadas; e c) riscos impossíveis de prever: são aqueles que não teriam sido identificados nem mesmo com as melhores técnicas de identificação.

Os riscos também podem ser classificados pelo seu impacto (Sommerville, 2011), conforme descritos a seguir: a) riscos de projeto: são aqueles que afetam o cronograma ou os recursos de projeto; b) riscos de produto: são aqueles que afetam a qualidade ou desempenho do produto (por exemplo, falha de um componente comprado que atrapalha o desempenho geral); e c) riscos de negócio: são aqueles que afetam a organização que desenvolve ou adquire o produto (por exemplo, outra empresa colocar um produto similar no mercado).

A Gerência de Riscos é um processo que visa planejar, organizar e controlar os recursos humanos e materiais de uma organização, com o intuito de reduzir a ocorrência dos riscos e minimizar seus efeitos sobre a organização ao mínimo possível. Também pode ser definida como um conjunto de técnicas que visa reduzir ao mínimo os efeitos das perdas acidentais, enfocando o tratamento dos riscos que possam causar danos pessoais, ao meio ambiente e/ou à imagem da empresa. Envolve antecipar os riscos que podem afetar o cronograma do projeto ou a qualidade do software e tomar medidas para evitar tais riscos (Hall, 1998; Ould, 1999 apud Wazlawick, 2013).

O gerenciamento de riscos pode iniciar-se a partir de requisitos vagamente definidos, mudanças de requisitos devido às necessidades do cliente ou dificuldades de estimar tempo e recursos. O modelo de gerenciamento de riscos do Software Engineering Institute (SEI) (Carr et al., 1993 apud Wazlawick, 2013), é bastante difundido e conhecido, e envolve seis atividades:

a) Identificação: antes que os riscos possam ser tratados eles precisam ser identificados.

b) Análise: a análise transforma a lista de riscos potenciais em um documento mais útil para o gerente do projeto, pois a partir dela os riscos são priorizados e o gerente pode se concentrar nos riscos mais importantes sem perder tempo com os insignificantes.

c) Planejamento: o planejamento quanto aos riscos permite ao gerente de projeto prevenir problemas, em geral, de três formas: 1) planejando e executando planos 
para reduzir a probabilidade do risco ocorrer; 2) planejando e executando planos para reduzir o impacto do risco, caso ocorra; e 3) planejando as atividades de recuperação de projeto, caso o risco efetivamente ocorra.

d) Rastreamento: o rastreamento (ou monitoramento) de riscos consiste em avaliar, ao longo do projeto, as propriedades dos riscos. O rastreamento deve ser baseado em métricas de avaliação de risco, por exemplo, identificador, descrição, probabilidade, impacto, importância, dentre outros.

e) Controle: em função de mudanças no status de um risco, alguns planos podem ter que ser executados. Muitas vezes talvez seja necessário improvisar a resposta ao problema causado pelo risco.

f) Comunicação: a comunicação é um processo fundamental ao longo de um projeto de software, especialmente em relação à prevenção e ao tratamento de riscos. Assim, não há uma atividade específica para a comunicação de riscos, pois se trata de uma prática que permeia todas as outras atividades.

\section{Processos de Gerência de Riscos Implantados em Empresas}

Para levantar processos de gerência de riscos implantados em empresas com o intuito de selecionar o mais adequado para utilizar neste trabalho, foi conduzido um levantamento bibliográfico na literatura. Para isso, foram realizadas buscas nos anais de dois eventos brasileiros da área de interesse, ou seja, WAMPS ${ }^{\ddagger}$ (Workshop Anual do MPS) e SBQS ${ }^{\S}$ (Simpósio Brasileiro de Qualidade de Software) no período de 2009 a 2015. Não foram considerados eventos internacionais durante o levantamento bibliográfico, pois o objetivo era identificar uma metodologia leve de gerenciamento de riscos, já aplicada e adequada à realidade das empresas brasileiras.

Como resultados do levantamento, foram encontrados alguns trabalhos (Islam, 2011; Mendes e Oliveira; 2014; Gonçalves, 2015), sendo que apenas um apresenta em detalhes como aplicar uma metodologia ágil para gerência de riscos, denominada RisAgi (Neto et al., 2013).

A metodologia RisAgi (Riscos Ágeis) foi concebida para possibilitar o gerenciamento das incertezas envolvidas em projetos de desenvolvimento de software. Essas incertezas podem ser entendidas como riscos e/ou impedimentos. Essa metodologia foi descrita passo a passo e necessita de poucos recursos humanos e financeiros. Devido a essas peculiaridades, essa metodologia foi selecionada para auxiliar na implantação da gerência de riscos no módulo $A_{1}$ pertencente ao projeto TranWeb do setor público do MS. Essa metodologia é descrita em mais detalhes na próxima seção.

\subsection{Metodologia RisAgi}

A metodologia RisAgi foi desenvolvida para ser uma solução de gestão ágil de riscos para projetos de desenvolvimento de software, contemplando a definição de um fluxo

\footnotetext{
* edições 2009 à 2015.

$\S$ edições 2010, 2014 e 2015.
} 
de atividades, papéis, cerimônias e um conjunto de produtos de trabalho (Neto et al., 2013). Na Figura 1 é ilustrado o ciclo de vida da RisAgi. A metodologia é baseada em práticas adotadas por metodologias ágeis, como o Scrum (Beedle e Schwaber, 2001). Sendo assim, tem foco no gerenciamento das incertezas dos projetos, com o objetivo de obter a melhor qualidade possível do produto final.

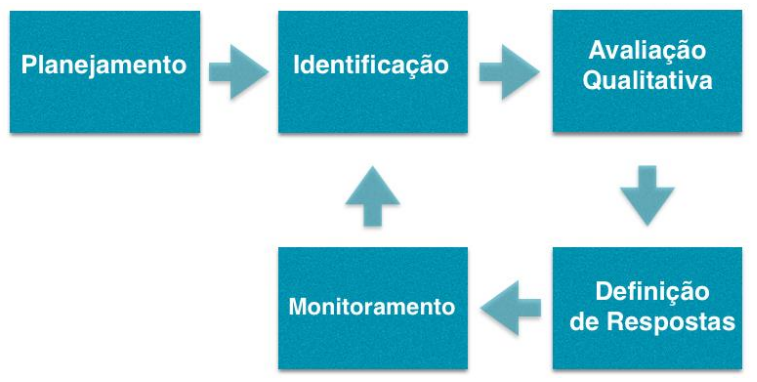

Figura 1. Ciclo de vida do RisAgi (Neto et al., 2013)

Para implantar a metodologia RisAgi é necessário entender o seu funcionamento. Ela possui dois papéis bem definidos: Guardião de Riscos e a Equipe de Riscos. O guardião de riscos garante o entendimento e a aplicação correta das atividades do projeto, monitora a equipe e os riscos, sendo uma ponte entre os stakeholders e a equipe. A equipe de riscos deve ser multifuncional, sem especialização e é responsável pela identificação, avaliação e definição das respostas aos riscos.

Esta metodologia utiliza artefatos como: Quadro de Riscos, Backlog de Riscos, Categoria dos Riscos, Burnup de Riscos e Cartões de Contingência e Mitigação. O Quadro de Riscos dá transparência a todos os envolvidos no processo de gerenciamento de riscos, facilita o monitoramento e a visualização da severidade dos riscos ao longo do projeto. O Backlog de Riscos é atualizado à medida que se aprende mais sobre o projeto. A Equipe de Risco deve manter o Backlog de Risco atualizado e disponível a todos os interessados no projeto. A Categoria dos Riscos contém todas as categorias, as quais servem para agrupar os riscos existentes no projeto e é criada, mantida e disponibilizada pela Equipe de Risco. O Burnup de Riscos é utilizado para monitorar a severidade dos riscos ao longo do projeto e é representado por meio de um gráfico. Qualquer mudança significativa nesse gráfico, o Guardião deve acionar a Equipe de Risco para realizar uma análise do ocorrido. Os Cartões de Contingência e de Mitigação descrevem as ações a serem tomadas para contingenciar os riscos e para diminuir a probabilidade da ocorrência dos mesmos.

As reuniões realizadas por esta metodologia são chamadas de cerimônias e podem ser definidas como: i) cerimônia de iniciação, onde é feita a apresentação e a realização da fase de planejamento da gerência de riscos no projeto; ii) cerimônia de Jogo de Risco, onde os riscos são identificados, analisados qualitativamente e as respostas aos riscos são definidas; e iii) cerimônia de Monitoramento e Revisão, onde os processos são realinhados.

\section{Gerência de Riscos no Projeto TranWeb}

O projeto TranWeb está sendo desenvolvido por uma empresa terceirizada que presta serviços para o setor público do MS. Como qualquer órgão público, a empresa que está 
desenvolvendo este projeto foi definida por meio de uma licitação. Para dar início ao desenvolvimento desse projeto, devido a sua dimensão e complexidade, foi necessário subdividi-lo em diversos módulos. $\mathrm{O}$ módulo $\mathrm{A}_{1}$, utilizado neste trabalho, é um dos módulos do projeto TranWeb. No projeto TranWeb estão sendo utilizados a linguagem de programação Java* ${ }^{* *}$ e o Sistema de Gerenciamento de Banco de Dados (SGBD) SQL Server $2014^{\dagger \dagger}$.

A equipe de desenvolvimento é formada por 23 pessoas, distribuídas da seguinte forma: dois desenvolvedores responsáveis pelo front-end, sete desenvolvedores responsáveis pelo back-end, seis analistas de sistema, quatro gerentes de projeto, um responsável pelo suporte técnico, dois DBAs e um testador. Para realizar o levantamento dos requisitos, os analistas se baseiam nas informações do sistema atual com apoio da engenharia reversa, nas regulamentações previstas em lei e nos chefes dos setores que utilizam os sistemas.

A equipe de analistas levantam os requisitos, criam os modelos de dados, diagrama de fluxos de negócio e casos de uso. Toda documentação elaborada pelos analistas é utilizada pelos DBAs, desenvolvedores e testadores. Os DBAs são responsáveis pela criação do modelo físico de dados e os desenvolvedores são responsáveis por implementar as regras e comportamentos definidos na documentação. Os testadores utilizam a documentação para a criação de casos de testes. Os gerentes de projeto são responsáveis pelo apoio e monitoramento das atividades do projeto e também pela gerência de prazos e custos. Sendo assim, todas as etapas do projeto TranWeb devem ser consideradas durante a aplicação da metodologia RisAgi.

Neste projeto, a duração e o escopo de uma release são definidos em reuniões com os clientes. Nosso cliente principal é o setor público do MS, porém o gerente da empresa terceirizada também se torna cliente devido a responsabilidade que o mesmo assumiu perante o órgão.

A metodologia RisAgi foi aplicada em um ciclo de desenvolvimento (release) do módulo $A_{1}$. Ficou definido que o papel de Guardião de Riscos seria de responsabilidade de três autores deste trabalho. Para atender o aspecto multifuncional da Equipe de Riscos, exigido pela metodologia, ela foi estruturada da seguinte forma: um DBA, dois gerentes de projeto, dois analistas, um testador e um desenvolvedor.

Antes de dar início a implantação da RisAgi no TranWeb, os autores apresentaram o objetivo do trabalho para a gerência de TI e definiram os membros do projeto que iriam participar da equipe de Gerência de Riscos. Ressalta-se que o treinamento sobre a metodologia RisAgi foi realizado nas cerimônias iniciais, conforme preconizado pela RisAgi. Devido a restrição de tempo para a condução da implantação inicial do RisAgi, foi acordado com a gerência do projeto que seriam considerados apenas os riscos negativos do projeto.

\footnotetext{
${ }^{* *}$ https://www.oracle.com/java/index.html

${ }_{\dagger}^{\dagger}$ https://www.microsoft.com/en-us/cloud-platform/sql-server
} 


\subsection{Implantação da Metodologia RisAgi no Projeto TranWeb}

A implantação da metodologia RisAgi foi guiada por nove reuniões (duas cerimônias de iniciação, duas cerimônias de jogo e cinco cerimônias de monitoramento e revisão, pois essas reuniões eram diárias) e foram gastas em média 12 horas, conforme gráfico apresentado na Figura 2.

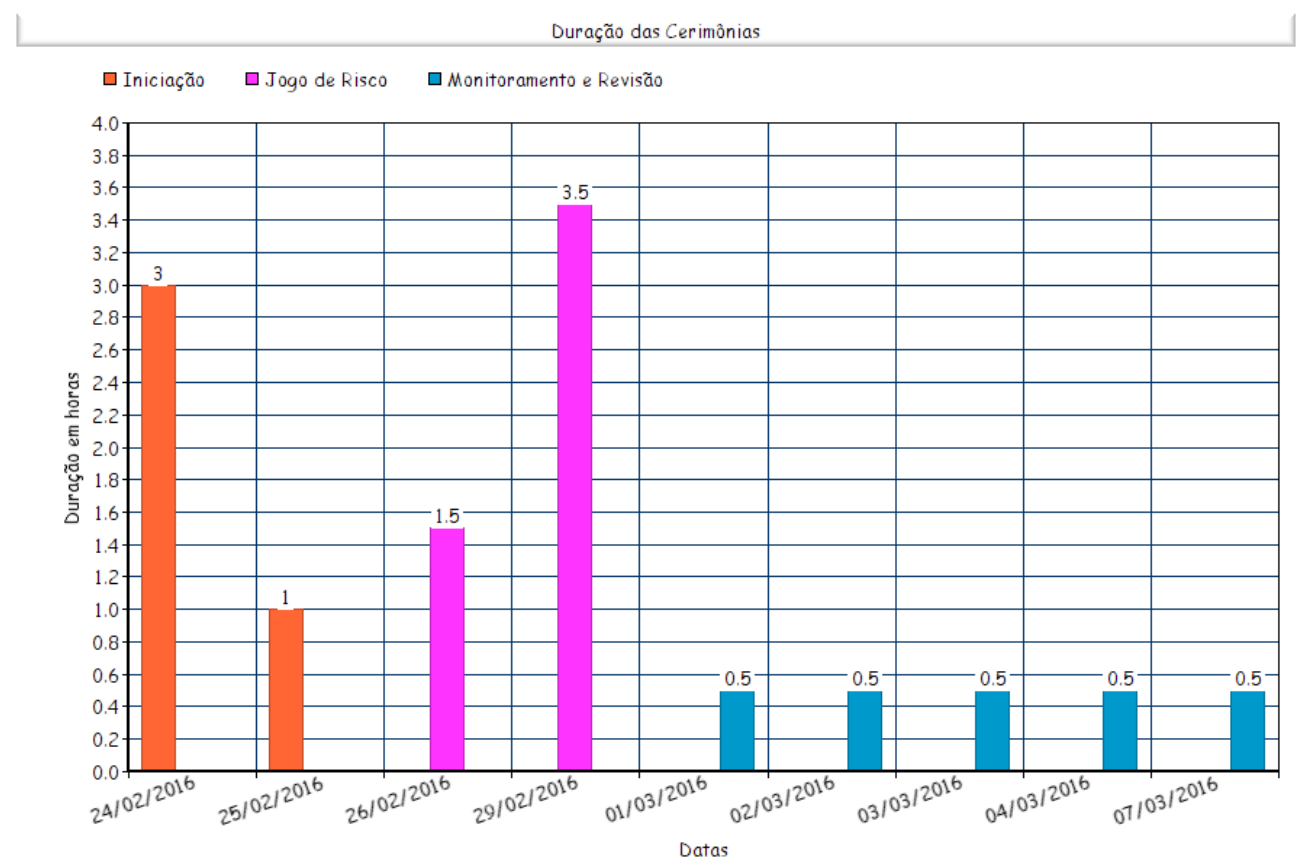

Figura 2. Tempo gasto (em horas) em cada reunião de implantação da RisAgi

Nas seções seguintes é descrita cada cerimônia realizada durante a implantação da RisAgi.

\subsubsection{Cerimônia de Iniciação}

A Cerimônia de Iniciação pertence a fase de planejamento, é de total responsabilidade do Guardião e foi realizada em dois dias (24 e 25 de Fevereiro/2016). No primeiro dia, foi apresentada a metodologia RisAgi para a equipe como também uma breve apresentação do módulo $\mathrm{A}_{1}$ levando em consideração, escopo, prazo, custo $\mathrm{e}$ expectativas. Para uma melhor compreensão da metodologia, foram utilizados slides e apresentados todos os materiais necessários para a sua implantação. No segundo dia, foi apresentada uma lista de categorias de riscos criada pelos guardiões em que a equipe teve o papel de definir quais categorias de riscos estão envolvidas no módulo $\mathrm{A}_{1}$. $\mathrm{Na}$ Figura 3 estão listadas todas as categorias criadas pelos guardiões, sendo que as categorias Subcontratações, Mercado e Financiamento foram desconsideradas pois não atendem o contrato de licitação firmado entre a empresa de desenvolvimento terceirizada e o setor público do MS, e a categoria Clima não pertence ao escopo do projeto.

Salienta-se que como o setor público ao qual o projeto TranWeb pertence ainda não tem uma metodologia para a gerência de riscos, optou-se por criar a lista de 
categorias de riscos com base em riscos já identificados na literatura e analisar a viabilidade de aplicação nesse projeto. A equipe ainda não possui maturidade em processos de software e, portanto, foram realizadas reuniões envolvendo os principais stakeholders do projeto para decidir quais riscos deveriam ser considerados. Espera-se que em iterações futuras, quando a equipe já estiver familiarizada com a atividade, a identificação de fatores de riscos ocorra de forma mais específica para o projeto.

Durante esta cerimônia de iniciação foram respondidas todas as dúvidas pertinentes ao projeto e a metodologia. Notou-se uma boa aceitação da equipe e uma rápida absorção dos conceitos expostos. A primeira reunião durou três horas e a segunda, apenas uma hora.

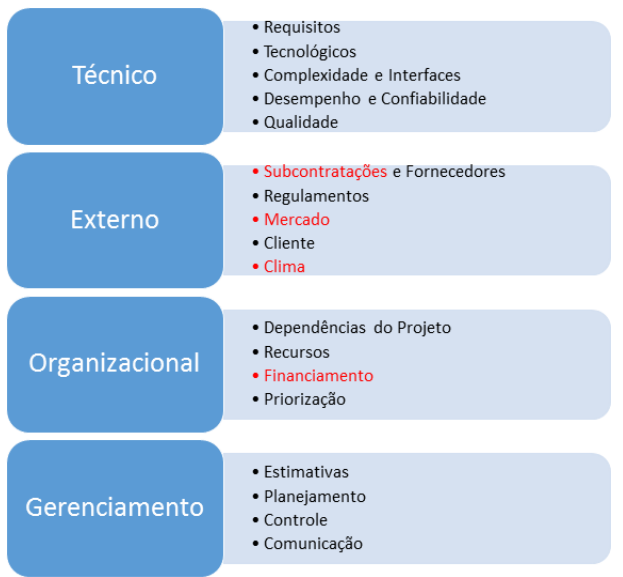

Figura 3. Lista de categoria de riscos

\subsubsection{Cerimônia de Jogo de Riscos}

A cerimônia de Jogo de Riscos durou dois dias e ocorreu durante as fases de Identificação, Avaliação Qualitativa e Definição de Resposta. Essa cerimônia tem como objetivo responder três questões: Q1: Quais são os riscos do projeto? Q2: Qual a severidade destes riscos? Q3: Como os riscos são tratados?

Para responder quais são os riscos do projeto (Q1), os Guardiões utilizaram a lista de Categorias de Riscos já definida na cerimônia anterior (Figura 3) para ajudar toda a Equipe de Riscos identificar os riscos do projeto pertencentes a cada categoria da lista. A técnica utilizada para essa etapa foi brainstorm, em que cada risco levantado foi justificado pelo membro da equipe que o levantou. Ao fim desta etapa foi produzido o Backlog de Riscos do projeto, com um total de doze riscos identificados. Na Tabela 1 é ilustrada uma parte desse backlog apenas para os riscos da categoria Externo.

Todos os membros da Equipe de Riscos puderam sugerir possíveis riscos, porém somente as sugestões consideradas como um risco por toda a equipe foram atribuídas ao projeto. Esta etapa da cerimônia durou uma hora e meia.

Com os riscos já definidos, deu-se início a segunda etapa da Cerimônia de Jogo de Riscos que responde qual a severidade (Q2) de cada item do Backlog de Riscos. A severidade de cada risco foi obtida de forma qualitativa por meio do resultado da multiplicação do impacto com a probabilidade do mesmo ocorrer. A avaliação dos 
riscos ocorreu com o apoio da técnica Planning Poker (Grenning, 2002) adaptada. A equipe selecionou o risco mais simples de todos, com estimativa de baixo impacto e menor probabilidade (menor carta do baralho), e usou esse risco como guia para todo o processo de avaliação de severidade dos riscos. Depois disso, seguindo a ordem apresentada no Backlog de Risco, cada item foi lido e avaliado. À medida que os riscos foram sendo avaliados, os mesmos foram colados no Quadro de Risco em seu devido quadrante. Ao fim desta etapa o Quadro de Riscos ficou preenchido, conforme a Tabela 2. Nessa tabela os identificadores dos riscos apresentados na Tabela 1 estão destacados com fonte em negrito.

Tabela 1. Backlog de Riscos

\begin{tabular}{|c|c|c|c|}
\hline \multirow{8}{*}{ Externo } & \#5 & Alteração da Lei & Regulamentos \\
\hline & \multicolumn{3}{|c|}{$\begin{array}{c}\text { Alteração de regras conforme a Lei. Essas alterações possuem data marcada para } \\
\text { entrar em vigor e não podem deixar de ser atendidas. }\end{array}$} \\
\hline & \#6 & Padronização de Sistemas & Fornecedores \\
\hline & \multicolumn{3}{|c|}{$\begin{array}{l}\text { Unificar dados de vários sistemas diferentes. O novo sistema deve abranger dados de } \\
\text { todos os sistemas. }\end{array}$} \\
\hline & $\# 7$ & Alterações de Requisitos & Cliente \\
\hline & \multicolumn{3}{|c|}{ Alteração de Requisitos informados pelos clientes } \\
\hline & $\# 8$ & $\begin{array}{c}\text { Diferença de requisitos entre os setores } \\
\text { envolvidos }\end{array}$ & Cliente \\
\hline & \multicolumn{3}{|c|}{ Cada setor envolvido exige regras ou requisitos diferentes para a mesma aplicação } \\
\hline
\end{tabular}

Tabela 2. Quadro de Riscos - Severidade dos Riscos

\begin{tabular}{|c|c|c|c|}
\hline Impacto & $\begin{array}{c}\text { Alto } \\
\text { (valor 4) }\end{array}$ & $\begin{array}{c}\text { Médio } \\
\text { (valor 3) }\end{array}$ & $\begin{array}{c}\text { Baixo } \\
\text { (valor 2) }\end{array}$ \\
\hline $\begin{array}{c}\text { Alta } \\
\text { (valor 4) }\end{array}$ & $\# 7$ & $\# 9$ & \\
\hline Média & $\# 10$ & $\# 11$ & \\
(valor 3) & $\# 2$ & & \\
\hline Baixa & $\# 3$ & $\# 8$ & $\# 12$ \\
(valor2) & $\# 1$ & & \\
\hline
\end{tabular}

Para completar esta etapa, a equipe levou duas horas e meia. Acredita-se que a medida que as práticas da metodologia RisAgi se tornem um hábito, os envolvidos poderão finalizar esta etapa da cerimônia mais rapidamente. Observou-se também que foi muito difícil para aqueles que não conheciam a técnica Planning Poker opinarem de forma coerente e por isso eles opinavam de forma intermediária para a maioria dos 
riscos. Acredita-se que isso também irá melhorar a medida que a técnica for aplicada com mais frequência.

A última etapa da Cerimônia de Jogo de Riscos esclarece como os riscos serão tratados (Q3). Para isso, o Quadro de Riscos foi utilizado e foram criadas respostas de mitigação e contingência para cada um dos riscos. Os riscos foram classificados como oportunidades ou ameaças (cores diferentes são utilizadas, por exemplo, cor azul para oportunidade e cor vermelha para ameaça). Como dito anteriormente, apenas ameaças serão consideras devido a solicitação da equipe envolvida. A técnica Opinião Especializada (PMI, 2004) foi utilizada nessa etapa. Essa técnica divide os riscos entre os membros e cada membro da Equipe de Riscos define as respostas de mitigação e contingência relacionadas aos riscos que estão sob sua responsabilidade. Com isso, cada membro evidencia o seu comprometimento ao escrever seu nome nos post-its. Cada membro escreveu sobre um ou dois riscos. Ao fim desta etapa, os cartões de contingência e de mitigação foram preenchidos para todos os riscos identificados. Devido a limitação do espaço, a Tabela 3 apresenta o cartão de contingência do risco \#5 e a Tabela 4 apresenta o cartão de mitigação desse risco.

Durante a última etapa, nenhuma dificuldade ou problema foi notado e levou apenas uma hora para que os envolvidos finalizassem os cartões. Os Guardiões acompanharam o andamento do projeto e a Equipe de Riscos manteve os documentos utilizados sempre atualizados.

Tabela 3. Cartão de contingência do risco \#5

\begin{tabular}{|l|l|}
\hline$\# 5$ & Risco: Alteração da Lei \\
\hline Quando o plano de contingência deve ser acionado: Quando for constatada alteração de Lei. \\
\hline $\begin{array}{l}\text { O que deve ser feito para contingenciar o risco: Será feita uma análise dos impactos para verificar qual será a } \\
\text { melhor decisão para projetar, documentar e implementar as mudanças provocadas pela alteração de Lei. }\end{array}$ \\
\hline $\begin{array}{l}\text { Como o risco será contingenciado: Serão apresentadas sugestões para toda equipe, que decidirá em conjunto pela } \\
\text { mais adequada. Todas as particularidades da sugestão escolhida serão documentadas para que seja implementada. }\end{array}$ \\
\hline
\end{tabular}

Tabela 4. Cartão de mitigação do risco \#5

\begin{tabular}{l} 
\#5 \\
Descrição do risco: Alteração da Lei \\
\hline $\begin{array}{l}\text { O que deve ser feito para mitigar o risco: O setor jurídico deve comunicar os analistas sobre mudanças em leis, } \\
\text { publicados no Diário Oficial, que afetam o sistema TranWeb. }\end{array}$ \\
$\begin{array}{l}\text { Como o risco deve ser mitigado: Assim que as alterações da Lei forem identificadas, os analistas poderão } \\
\text { começar a criar os cenários de sugestões antes do cliente comunicar a alteração da Lei. }\end{array}$ \\
$\begin{array}{l}\text { Porque o risco deve ser mitigado: Antecipando a análise, é possível encontrar uma solução detalhada e factível } \\
\text { em tempo hábil, sem prejudicar o andamento do projeto. }\end{array}$
\end{tabular}

\subsubsection{Cerimônia de Monitoramento e Revisão}

Durante a Cerimônia de Monitoramento e Revisão, os Guardiões criaram e atualizaram o gráfico do Burnup (Figura 4) à medida que um risco ocorreu. 
A cerimônia de monitoramento e revisão ocorreu durante cinco dias (1, 2, 3, 4 e 7 de Março/2016), cerca de meia hora por dia, perfazendo um total de aproximadamente três horas. À medida que os riscos ocorriam, eles eram sinalizados com um ponto no gráfico. Apenas dois riscos ocorreram durante estas cerimônias e estão identificados por \#12 e \#10.

Cada ponto exibido no gráfico Burnup contém informações como a data de ocorrência do risco e o número da severidade do risco, que foi obtida pela multiplicação da probabilidade com o impacto do risco, com base na Tabela 2. Ao final das Cerimônias de Monitoramento e Revisão, a equipe gerou o Burnup, conforme gráfico exibido na Figura 4.

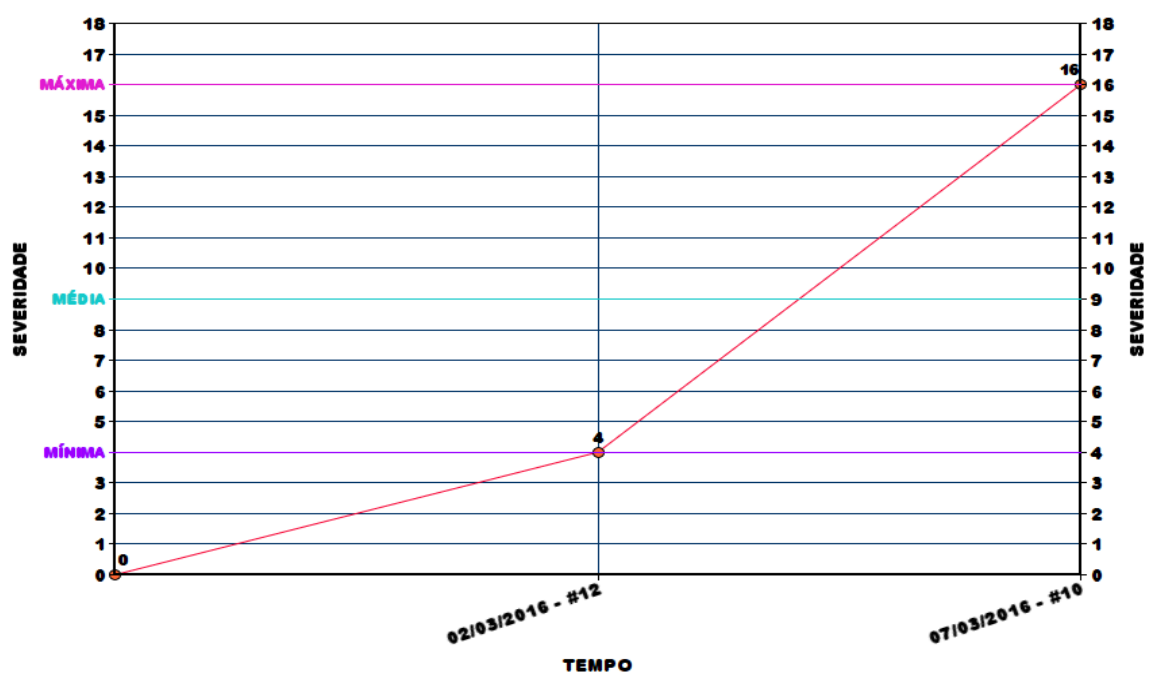

Figura 4. Gráfico Burnup

\section{Resultados Obtidos e Lições Aprendidas}

Ao final das reuniões, correspondentes às cerimônias da metodologia RisAgi, realizadas em um dos ciclos de desenvolvimento do módulo $A_{1}$, foi conduzida uma avaliação sobre a implantação de Gerência de Riscos no TranWeb. Para isso, foi elaborado um questionário avaliativo específico para este fim, o qual foi respondido por sete pessoas que participaram da implantação.

O questionário criado possui oito questões: uma questão para obter feedback sobre o treinamento oferecido, quatro questões de múltipla escolha sobre a metodologia RisAgi, e três questões abertas sobre pontos fortes e fracos da aplicação da metodologia para ajudar a implantação da gerência de riscos nos demais módulos do projeto TranWeb.

Os autores deste trabalho assumiram o papel de Guardiões durante a implantação, pois possuem domínio da metodologia, porém não responderam o questionário pois a opinião dos mesmos poderia afetar os resultados da opinião dos demais envolvidos.

A partir da compilação das respostas dos questionários, foi possível observar que a metodologia é totalmente conveniente para projetos que precisam de metodologias 
mais simplificadas, como é o caso do TranWeb. Também observou-se que a fase mais complexa é a Cerimônia de Jogo de Riscos, pois nela é necessário avaliar e classificar cada um dos riscos. Todos os participantes citaram que os artefatos gerados nas cerimônias são de fácil acesso e fácil visualização do acontecimento dos riscos.

Outras informações coletadas durante a avaliação estão apresentadas nas Figuras 5 a 9. Diante disso, observa-se que a maior parte da equipe envolvida acredita que o treinamento oferecido sobre a RisAgi foi amplamente satisfatório para a absorção dos conceitos e entendimento do funcionamento da metodologia. A falta de experiência com a metodologia, o curto período de tempo e a cobertura de apenas riscos negativos foram citados como pontos negativos, já a transparência das informações e a participação e opinião de todas as partes envolvidas da equipe foram consideradas como pontos positivos.

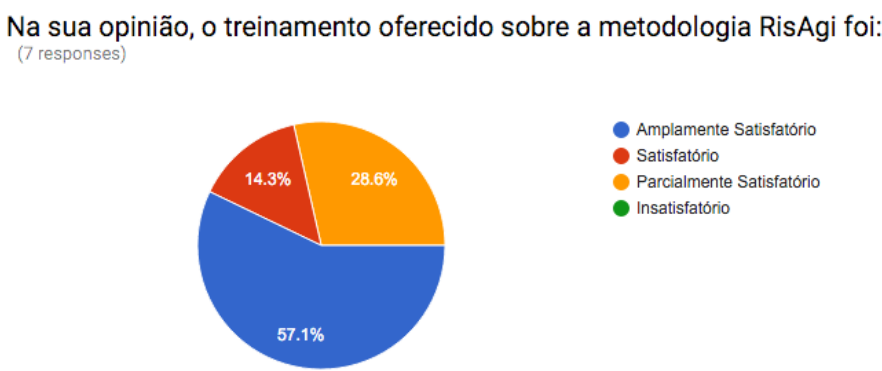

Figura 5. Questionário de avaliação da implantação da metodologia RisAgi (treinamento)

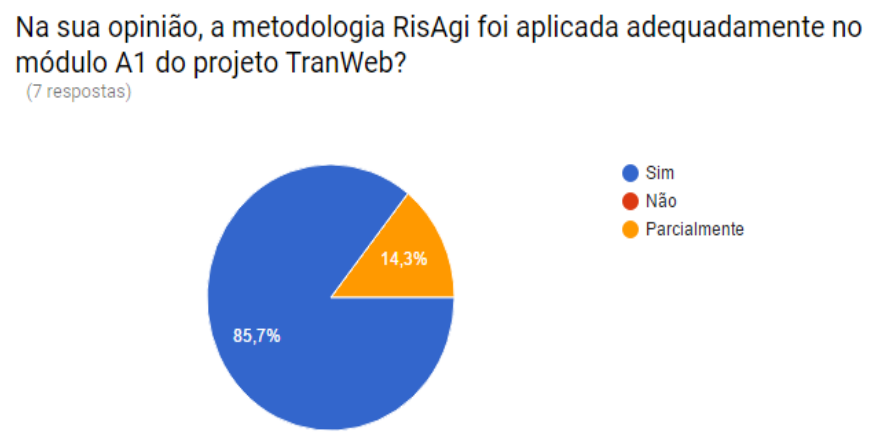

Figura 6. Questionário de avaliação da implantação da metodologia RisAgi (aplicação)

Na sua opinião, a metodologia RisAgi é um maneira conveniente de Gerenciar
Riscos em projetos ágeis? (7 responses)

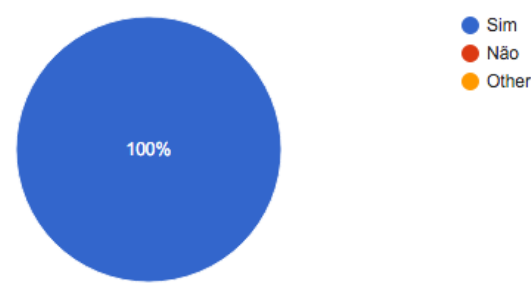

Figura 7. Questionário de Avaliação da Implantação da Metodologia RisAgi (Gerência de Riscos) 
A partir dos resultados da avaliação realizada, observa-se que a implantação da metodologia no módulo $\mathrm{A}_{1}$ servirá como base para os demais módulos do projeto TranWeb. À medida que as cerimônias se repetem, a equipe estará familiarizada com cada etapa e poderá executá-las de maneira simplificada e ágil. Além disso, foi possível observar que a metodologia RisAgi pode e deve ser implantada em projetos de software devido a facilidade de leitura do acontecimento dos riscos, fácil acesso as medidas de contingência e mitigação e delegação de responsabilidades de forma equilibrada.

A metodologia RisAgi poderia ser aplicada de forma eficiente nos demais módulos do projeto TranWeb? * (7 respostas)

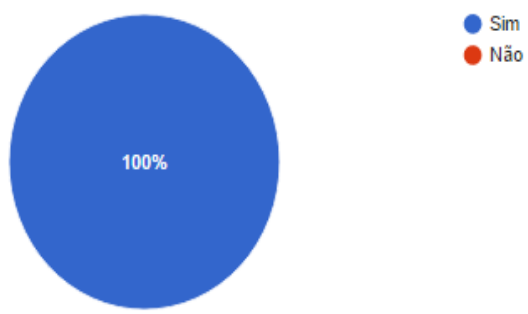

Figura 8. Questionário de Avaliação da Implantação da Metodologia RisAgi (eficiência)

Os artefatos da RisAgi permitiram visualizar facilmente os riscos do módulo A1 do projeto TranWeb?
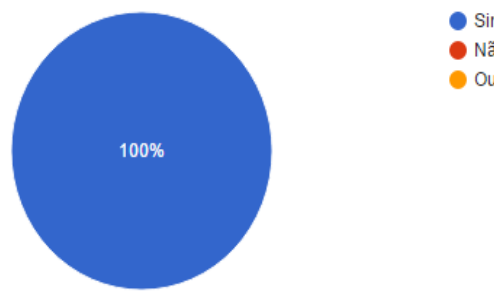

Não

Outros

Figura 9. Questionário de Avaliação da Implantação da Metodologia RisAgi (artefatos)

\section{Trabalhos Relacionados}

Mendes e Oliveira (2014) apresentaram uma proposta de metodologia para implementação do processo de Gerência de Riscos em organizações desenvolvedoras de software. A proposta visa atender às boas práticas apresentadas em alguns dos principais modelos e normas relacionados à qualidade de software, tais como ISO/IEC 12207 e PMBoK. O projeto teve o objetivo de alcançar vários resultados, tais como especificação do conjunto de boas práticas em Gerência de Riscos; definição do conjunto de técnicas e métodos usados na implementação da gerência de riscos e proposição de um modelo de processo de gerência de riscos.

Gonçalves (2015) identificou um conjunto de riscos que podem comprometer o planejamento e a condução de iniciativas de MPS baseadas nos modelos MR-MPS-SW e CMMI-DEV. Foram obtidas 135 fichas de riscos, detalhando informações como 
categoria do risco, causas, consequências, eventos, ações de controle e seus respectivos efeitos. Cada ficha também associa informações de contexto de ocorrência do risco como: o objetivo e a duração das iniciativas de MPS, as estratégias de implantação utilizadas, o modelo de maturidade, o nível pretendido e alcançado e, ainda, o framework ou a metodologia de desenvolvimento adotado. As organizações podem utilizar o conteúdo das fichas como entrada para um processo de identificação ou análise de riscos, de forma a aumentar a possibilidade dos objetivos da iniciativa de MPS serem alcançados.

Islam (2011) apresenta um framework para gerenciamento de riscos orientado a objetivos. O framework possui os seguintes níveis de abstração: objetivos do projeto; identificação de obstáculos que impeçam que o projeto atinja seus objetivos (fatores de riscos ou perfil dos riscos); para cada fator de risco, identificação de consequências (definição dos riscos); e definição de como deve ser realizado o tratamento e monitoramento dos riscos.

Nota-se, portanto, que há diversas tentativas de identificar riscos, em especial, aqueles que possam trazer grandes danos às organizações caso não sejam devidamente gerenciados. Há um menor número de trabalhos na literatura que indiquem experiências práticas na gestão de riscos e, assim, este trabalho tentar contribuir nesse sentido, indicando as principais tarefas cumpridas e os resultados obtidos.

\section{Conclusão}

A Gerência de Riscos é negligenciada em muitos projetos de software e, em muitos casos, quando considerada, não é implantada por completo. Tendo em vista que a gerência de risco tem papel importante para o sucesso de projetos de software e dada a necessidade desse tipo de processo nos projetos de software do setor público do MS, este trabalho selecionou uma metodologia simples e ágil denominada RisAgi. Essa metodologia foi implantada em um ciclo de desenvolvimento do módulo $\mathrm{A}_{1}$ que é parte do sistema TranWeb, sendo que sete pessoas participaram dessa implantação, com pelo menos um membro de cada etapa do projeto.

A metodologia RisAgi foi de fácil aprendizado e gerou um feedback positivo. Com uma definição clara de cada etapa, foi possível colocar a metodologia em prática com facilidade e atingir os objetivos de cada cerimônia. Os artefatos foram elaborados de forma simples e clara e por isso não consumiram tanto tempo como nas metodologias tradicionais. Mesmo com uma documentação mais enxuta, existe documentação suficiente para entender os riscos e as decisões a serem tomadas quando os mesmos ocorrerem. Como ponto fraco desta implantação tem-se a falta de tempo para a observação dos riscos positivos.

Para futuros trabalhos, sugere-se o levantamento de todos os riscos possíveis, ou seja, tanto os riscos negativos como também os positivos nos demais módulos do projeto TranWeb; bem como a adoção da RisAgi em diferentes tipos de projetos para levantar os pontos positivos e negativos da metodologia em diferentes contextos. Para um monitoramento mais adequado dos riscos e também uma melhor visualização dos mesmos e, consequentemente, para uma gerência de riscos mais efetiva, é importante aplicar a metodologia RisAgi desde o início do projeto de software. 


\section{Referências}

Beedle, M.; Schwaber, K. (2001) “Agile Software Development With SCRUM”, São Paulo: Pearson, 1.ed.

Chamon, M. A.; Carvalho, T. R. (2003) "Gerenciamento de riscos em projetos espaciais". In: IV Congresso Ibero-Americano De Gerência de Projetos, São Paulo.

Gonçalves, E. D. (2015) "Riscos em Iniciativas de Melhoria de Processos de Software Baseadas no MR-MPS-SW e no CMMI-DEV: Uma Investigação no Contexto Brasileiro". Dissertação, UFRJ, 283 páginas.

Grenning, J. (2002) "Planning Poker or How to avoid analysis paralysis while release planning". Hawthorn Woods: Renaissance Software Consulting, 3.

Islam, S. (2011) "Software development risk management model-a-goal-driven approach". Thesis, Institute für Informatik, Technische Universität München, Munique.

Laudon, K. C.; Laudon, J. P. (2015) "Sistemas de Informação Gerenciais", São Paulo: Pearson, 11.ed.

Mendes, H. J. P. S.; Oliveira, S. R. B. (2014) "Uma Proposta de Metodologia para Gerenciamento de Riscos em Projetos de Software aderente a Modelos e Normas de Qualidade de Processo de Software". In: XII Workshop de Teses e Dissertações em Qualidade de Software do XIII SBQS, Blumenau, SC, p.19-24.

Neto B.; Cardoso P.; Bezerra S. (2013) "Uma Metodologia Ágil para Gestão de Risco em Projetos de Desenvolvimento de Software", In: WAMPS 2013, Campinas, SP, p. 130-141.

PMI (2012) "Um Guia do Conjunto de Conhecimentos em Gerenciamento de Projetos Guia PMBOK $^{\circledR}$,, São Paulo: Saraiva, 5.ed.

Pressman, R. S. (2016) Engenharia de Software: Uma Abordagem Profissional, Porto Alegre: AMGH, 8.ed.

Sommerville, I. (2011) "Engenharia de Software”, São Paulo: Pearson, 9.ed.

Wazlawick, R. (2013) "Engenharia de Software: Conceitos e Práticas", São Paulo: Campus, 1.ed. 